\title{
Rapid Determination of Simple Polyphenols in Grapes by LC Using a Monolithic Column
}

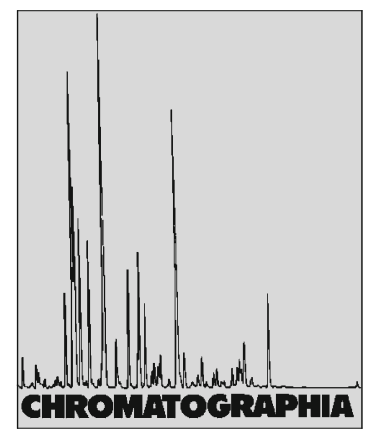

2010, 72, 417-424

\author{
Ali Liazid', Gerardo F. Barbero' ${ }^{1}$, Miguel Palma ${ }^{1, \bowtie}$, Jamal Brigui ${ }^{2}$, Carmelo G. Barroso' \\ ${ }^{1}$ Grupo de Investigación Químico Analítico del Vino y Productos Agroalimentarios, Departamento de Química Analítica, Facultad de \\ Ciencias, Universidad de Cádiz, Apdo 40, 11510 Puerto Real, Cádiz, Spain; E-Mail: miguel.palma@uca.es \\ 2 Département de Génie Chimique, Faculté des Sciences et Techniques de Tanger, Université Abdelmalek Essaâdi, Tanger, Morocco
}

\begin{abstract}
The development of a rapid, reliable and reproducible LC method for the determination and quantification of 13 polyphenols (gallic acid, protocatechuic aldehyde, gentisic acid, catechin, vanillinic acid, caffeic acid, vanillin, epicatechin, syringaldehyde, p-coumaric acid, ferulic acid, sinapic acid and resveratrol) in grapes and derived products is reported. The polyphenols were separated in less than $8 \mathrm{~min}$. Employed was an RP-18e $(100 \mathrm{~mm} \times 4.6 \mathrm{~mm})$ monolithic type column. A gradient method with the following solvents was utilised for the chromatographic separation: A: $90 \%$ water, $2 \%$ acetic acid in methanol, and B: $90 \%$ methanol, $2 \%$ acetic acid in water. Two detectors in series were employed: a $\mathrm{UV}-\mathrm{V}$ is detector and a fluorescence excitation/emission detector. Influence of temperature $\left(15-40{ }^{\circ} \mathrm{C}\right)$ and solvent flow rate $\left(2-5 \mathrm{~mL} \mathrm{~min}{ }^{-1}\right)$ on the separation were studied, and $25^{\circ} \mathrm{C}$ and $2.5 \mathrm{~mL} \mathrm{~min}{ }^{-1}$ were found to be the optimum conditions. The relative standard deviations of the resulting peak areas, for both intra- and inter- experiments, were less than 2.4 and $2.6 \%$, respectively. Finally, the developed method has been utilised for the quantification of the polyphenols in real samples.
\end{abstract}

\section{Keywords}

Column liquid chromatography

Monolithic column

Phenolics

Grapes and must

\section{Introduction}

Phenolic compounds represent a large number of compounds of great interest for the natural products chemistry. These compounds are widely distributed in plants, especially in fruits and their derivatives. They can be defined chemically as the compounds characterised by incorporating in their structure at least one aromatic ring containing one free or substituted hydroxyl group (esters, methyl-esters, glycosides, etc.) [1, 2].

In recent years there has been increasing interest in the determination of phenolic compounds in fruits, wines and other foods. The reasons for this interest are: (i) these compounds play an important role in the flavour and colour of foods [3]; (ii) they act as natural antioxidants [4]; and (iii) various interesting biological activities have been found [5], including those related to human health [6].

Many modern techniques, such as liquid chromatography (LC) [7-11], have been employed to characterise and identify phenolic compounds in foods. Reverse phase-liquid chromatography (RP-LC) using conventional RP $\mathrm{C} 18$ columns has proved to be the most appropriate technique for determining these compounds sufficiently sensitive and precise. Unfortunately, chromatographic analyses often take excessive time and sometimes must be preceded by a time-consuming sample cleanup step [12].

However, non-conventional monolithic supports for column packings are increasingly attracting the interest of researchers $[13,14]$. Due to their rigid 
<smiles>[R]c1cc(C(=O)O)c([R])c([R])c1[R]</smiles><smiles>[R]c1cc(C=O)cc([R])c1[R]</smiles><smiles>[R]c1cc(/C=C/C(=O)O)cc([R])c1[R2]</smiles><smiles>Oc1cc(O)c2c(c1)O[C@H](c1ccc(O)c(O)c1)[C@H](O)C2</smiles>

$\mathrm{R} 1, \mathrm{R} 3=\mathrm{H}, \mathrm{R} 2=\mathrm{OH}$ $\mathrm{R} 1, \mathrm{R} 2=\mathrm{OH}, \mathrm{R} 3=\mathrm{H}$ $\mathrm{R} 1=\mathrm{OCH} 3, \mathrm{R} 2=\mathrm{OH}, \mathrm{R} 3$

\section{p-Coumaric acid Caffeic acid} Ferulic acid Sinapic acid<smiles>Oc1cc(O)c2c(c1)O[C@H](c1ccc(O)c(O)c1)[C@H](O)C2</smiles>

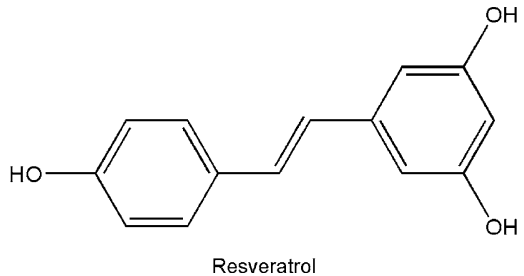

Resveratrol

Fig. 1. Chemical structures of the compounds utilised in the development of the method

Table 1. Retention times $(\min )(n=3)$ of the different polyphenols employing methods of separation in isocratic regime

\begin{tabular}{|lllllll|}
\hline Compound & \multicolumn{7}{l}{ Methods } & & & & \\
\cline { 2 - 7 } & 1 & 2 & 3 & 4 & 5 & 6 \\
& $(100 \% \mathrm{~A})$ & $(97 \% \mathrm{~A})$ & $(94 \% \mathrm{~A})$ & $(91 \% \mathrm{~A})$ & $\begin{array}{l}(88 \% \mathrm{~A}) \\
(85 \% \mathrm{~A})\end{array}$ \\
\hline Gallic acid (1) & 0.88 & 0.85 & 0.82 & 0.78 & 0.77 & 0.75 \\
Protocatechuic & 1.70 & 1.53 & 1.37 & 1.26 & 1.16 & 1.08 \\
$\quad$ aldehyde (2) & & & & & & \\
Gentisic acid (3) & 1.95 & 1.77 & 1.59 & 1.46 & 1.34 & 1.24 \\
(+)-Catechin (4) & 2.20 & 1.80 & 1.48 & 1.28 & 1.12 & 1.02 \\
Vanillinic acid (5) & 2.89 & 2.48 & 2.11 & 1.84 & n.a. & n.a. \\
Caffeic acid (6) & 3.21 & 2.72 & 2.26 & 1.93 & n.a. & n.a. \\
Vanillin (7) & 4.07 & 3.38 & 2.78 & 2.37 & 2.03 & 1.78 \\
Epicatechin (8) & 5.63 & 4.14 & 3.03 & 2.33 & n.a. & n.a. \\
Syringic aldehyde (9) & n.a. & n.a. & 3.63 & 2.91 & 2.38 & 2.00 \\
p-Coumaric acid (10) & n.a. & n.a. & 4.01 & 3.36 & 2.83 & 2.40 \\
Ferulic acid (11) & 9.24 & 7.22 & 5.58 & 4.42 & 3.55 & 2.90 \\
Sinapic acid (12) & 13.35 & 9.75 & 7.07 & 5.27 & 4.03 & 3.15 \\
Resveratrol (13) & $>15$ & $>15$ & $>15$ & 13.80 & 10.11 & 7.53 \\
\hline
\end{tabular}

n.a. not available, overlapped peaks and porous structure, they enable higher solvent flows, shorter assay times, and fast column re-equilibration between runs [15]. To date, relatively few separations with monolithic columns have been described in the literature on the subject of phenols analysis [16-20].

Apers et al. [16] have used a monolithic column to obtain a reduction of 2.4 times in the separation time of isoflavones, compared to a conventional C-18 column. Chinnici et al. [17] separated the phenolic compounds of apple in less than 21 min using a monolithic column, whereas $55 \mathrm{~min}$ were needed to separate these compounds with a classical column [21].

Castellari et al. [13] were able to reduce the time for the separation of phenolic compounds in wine to $31 \mathrm{~min}$ using a monolithic column, whereas the separation of these compounds in wine with a C-18 column in RP-LC had previously required $120 \mathrm{~min}$ [22].

Besides LC with monolithic columns, a related technique, ultra performance liquid chromatography (UPLC), has also been used for these compounds. Very short separation methods have been developed in the last years, for example $3.2 \mathrm{~min}$ were needed for phenolics found in wines [23], $3.7 \mathrm{~min}$ for phenolics in spirits [24] and $9.5 \mathrm{~min}$ for phenolics in vanilla [25]. UPLC is a very attractive alternative to reduce the total analysis time, however a monolithic column allows for a similar time reduction using regular LC equipments.

This article describes the development of a new rapid and reproducible analysis method of 13 phenolic compounds representative for the various different families (catechins, hydroxycinnamic acids, hydroxybenzoic acids, stilbene, and benzoic aldehydes) by employing a monolithic column. Two detectors in series were utilised; this permits greater selectivity in the quantification of the compounds.

\section{Experimental}

\section{Chemical and Reagents}

Methanol and acetic acid (Merck, Darmstadt, Germany) used were LC 
grade. Water was supplied by a Milli-Q water purifier system from Millipore (Bedford, MA, USA). Phenolic standards were obtained from Sigma (St. Louis, MO, USA). The standards used were: gallic acid, protocatechuic aldehyde, gentisic acid, catechin, vanillinic acid, caffeic acid, vanillin, epicatechin, syringaldehyde, $p$-coumaric acid, ferulic acid, sinapic acid, and resveratrol, all of them with purity higher than $95 \%$. The chemical structures are shown in Fig. 1.

Stock solutions of the standards were prepared by dissolving all compounds in methanol and water $(50: 50, v / v)$ and then stored in a freezer at $-20{ }^{\circ} \mathrm{C}$. The stability of the stock solutions was monitored and no changes in concentrations were observed.

\section{Chromatographic Analysis}

The chromatographic analyses were carried out in a Dionex chromatographic system (Sunnyvale, CA, USA), consisting of an automated sample injector (ASI-100), pump (P680), thermostatic column compartment (TCC-100), a photodiode array detector (PDA-100), a fluorescence detector (RF 2000), a universal chromatography interface (UCI50) and Chromeleon 6.60 software. Phenolic compounds were separated using a Chromolith Performance PR-18e $(100 \mathrm{~mm} \times 4.6 \mathrm{~mm})$ monolithic column (Merck). The optimized gradient was as follows (time, solvent A): $0 \mathrm{~min}, 100 \%$; $1 \mathrm{~min}, 94 \%$; $4 \mathrm{~min}, 94 \%$; $5 \mathrm{~min}, 87 \%$; $6 \mathrm{~min}, 60 \%$; $9 \mathrm{~min}, 50 \%$; $14 \mathrm{~min}, 0 \%$.

The chromatographic separation was performed with a mixture of standards. The polyphenols were analysed by detection with photodiode array and fluorescence spectroscopy. In the $\mathrm{UV}-\mathrm{V}$ is spectra the wavelengths used for quantification were 260 and $320 \mathrm{~nm}$, while in fluorescence detection, two combinations of wavelengths were utilised for excitation/emission: 280/310 and $310 / 403$. The first combination was employed for the determination of catechin and epicatechin [26] and the second one for the determination of resveratrol [27].
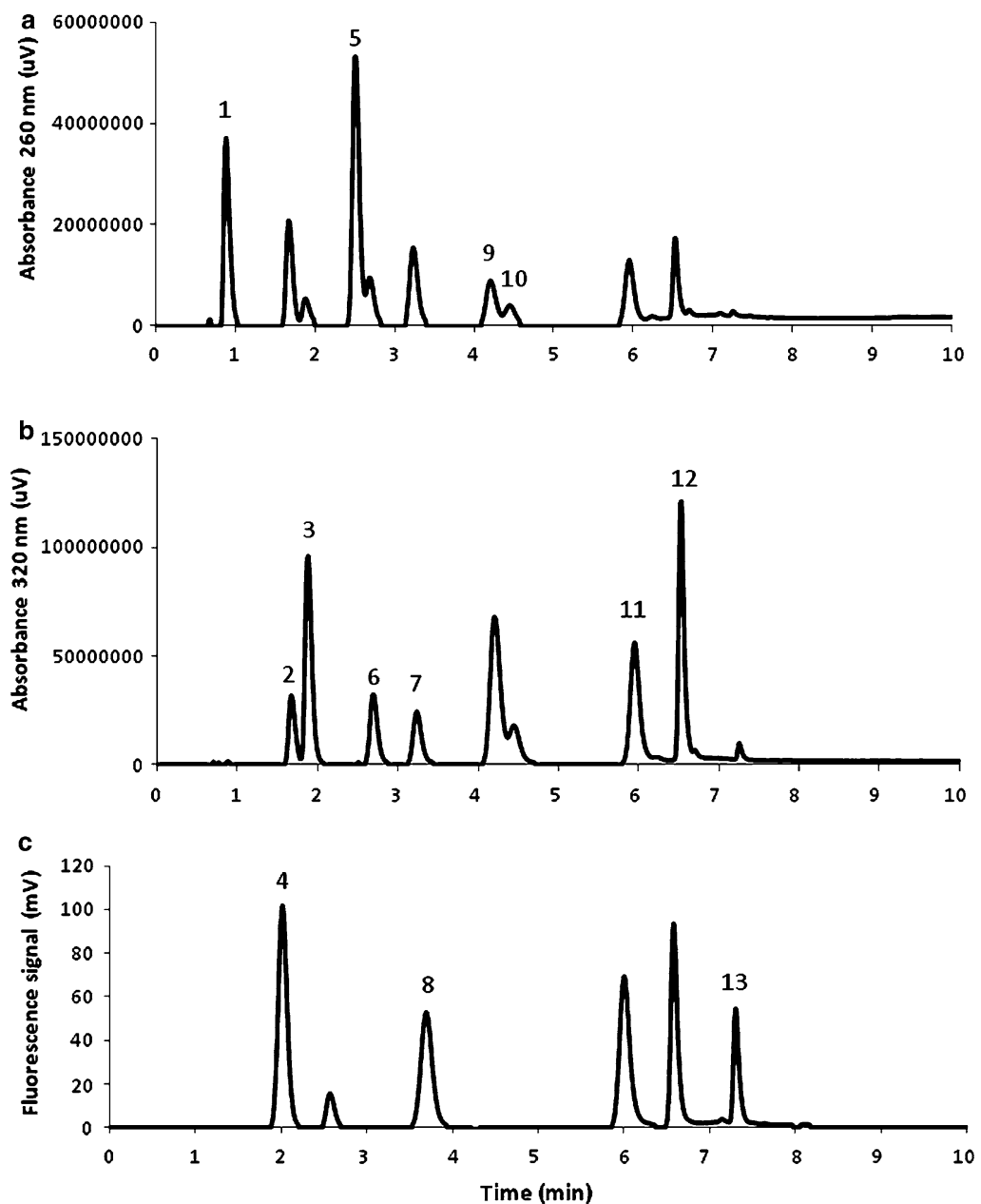

Fig. 2. Chromatograms obtained employing the method in gradient developed. Detection conditions: diode array detector: $\lambda=260 \mathrm{~nm}(\mathbf{a}), \lambda=320 \mathrm{~nm}$ (b). Fluorescence detector (excitation/emission) (c): 280/310 (from start until 7.0 min) and 310/403 (from 7.0 min until the end). Peak identification: $\mathbf{1}=$ gallic acid, $\mathbf{2}=$ protocatechuic aldehyde, $\mathbf{3}=$ gentisic acid, $\mathbf{4}=(+)$-catechin, $\mathbf{5}=$ vanillinic acid, $\mathbf{6}=$ caffeic acid, $\mathbf{7}=$ vanillin, $\mathbf{8}=$ epicatechin, $\mathbf{9}=$ syringic aldehyde, $\mathbf{1 0}=p$-coumaric acid, $\mathbf{1 1}=$ ferulic acid, $\mathbf{1 2}=$ sinapic acid, $\mathbf{1 3}=$ resveratrol

Table 2. Mean resolution $(n=3)$ of the chromatographic peaks obtained applying the method in gradient at different temperatures

\begin{tabular}{|c|c|c|c|c|c|}
\hline \multirow[t]{2}{*}{ Compound } & \multicolumn{5}{|c|}{ Temperature $\left({ }^{\circ} \mathrm{C}\right)$} \\
\hline & 15 & 25 & 30 & 35 & 40 \\
\hline Gallic acid & 5.09 & 5.19 & 5.05 & 4.79 & 4.42 \\
\hline Protocatechuic aldehyde & 1.17 & 1.20 & 1.16 & 1.01 & n.a. \\
\hline Gentisic acid & 2.82 & 3.45 & 3.42 & n.a. & n.a. \\
\hline$(+)$-Catechin & 2.35 & 2.82 & 2.86 & n.a. & n.a. \\
\hline Vanillinic acid & 1.05 & 1.07 & 0.86 & n.a. & n.a. \\
\hline Caffeic acid & 1.88 & 2.70 & 2.82 & n.a. & n.a. \\
\hline Vanillin & 3.44 & 4.26 & 4.03 & 3.22 & 2.82 \\
\hline Epicatechin & 5.29 & 9.54 & 9.79 & 8.39 & 11.78 \\
\hline Syringic aldehyde & 1.04 & 1.23 & n.a. & n.a. & n.a. \\
\hline$p$-Coumaric acid & 3.52 & 6.18 & n.a. & n.a. & n.a. \\
\hline Ferulic acid & 1.46 & 3.56 & 3.76 & 3.31 & 2.51 \\
\hline Sinapic acid & 3.16 & 5.33 & 5.35 & 5.14 & 4.38 \\
\hline Resveratrol & 4.68 & 5.50 & 5.78 & 5.06 & 5.64 \\
\hline
\end{tabular}

n.a. not available, overlapped peaks 
Table 3. Mean resolution $(n=3)$ of the chromatographic peaks obtained applying different flow rates of the mobile phase

\begin{tabular}{|c|c|c|c|c|c|c|c|}
\hline \multirow[t]{2}{*}{ Compound } & \multicolumn{7}{|c|}{ Flowrate $\left(\mathrm{mL} \mathrm{min}^{-1}\right)$} \\
\hline & 2 & 2.5 & 3 & 3.5 & 4 & 4.5 & 5 \\
\hline Gallic acid & 5.3 & 5.2 & 5.1 & 5.1 & 4.7 & 4.6 & n.a. \\
\hline Protocatechuic aldehyde & 1.3 & 1.2 & 1.2 & 1.2 & 1.2 & 1.1 & 1.0 \\
\hline Gentisic acid & 3.6 & 3.6 & 3.6 & 3.6 & 3.4 & 3.4 & 3.3 \\
\hline$(+)$-Catechin & 3.1 & 3.0 & 2.9 & 2.9 & 2.7 & 2.6 & 2.6 \\
\hline Vanillinic acid & 1.1 & 1.0 & 0.9 & 0.9 & 1.0 & 0.9 & 0.9 \\
\hline Caffeic acid & 2.9 & 2.9 & 2.8 & 2.8 & 2.6 & 2.5 & 2.5 \\
\hline Vanillin & 4.5 & 4.3 & 4.3 & 4.1 & 4.0 & 3.9 & 3.7 \\
\hline Epicatechin & 9.9 & 9.7 & 8.9 & 7.9 & 7.6 & 7.4 & 7.2 \\
\hline Syringic aldehyde & 1.3 & 1.1 & n.a. & n.a. & n.a. & n.a. & n.a. \\
\hline$p$-Coumaric acid & 5.6 & 6.2 & n.a. & n.a. & n.a. & n.a. & n.a. \\
\hline Ferulic acid & 2.2 & 3.6 & 4.1 & 4.5 & 3.8 & 3.7 & 3.6 \\
\hline Sinapic acid & 5.9 & 6.9 & 6.3 & 7.5 & 5.9 & 5.1 & 6.2 \\
\hline Resveratrol & 5.4 & 5.5 & 5.4 & 5.3 & 4.6 & 4.6 & 5.5 \\
\hline
\end{tabular}

n.a. not available, overlapped peaks

Table 4. Calibration curves of the compounds analysed

\begin{tabular}{|c|c|c|c|c|c|c|c|}
\hline Compound & $\lambda(\mathrm{nm})$ & $a$ & $b$ & $r^{2}$ & $\mathrm{LD}\left(\mathrm{mg} \mathrm{L}^{-1}\right)$ & $\mathrm{LQ}\left(\mathrm{mg} \mathrm{L}^{-1}\right)$ & $\begin{array}{l}\text { Range of } \\
\text { concentration }\left(\mathrm{mg} \mathrm{L}^{-1}\right)\end{array}$ \\
\hline Gallic acid & $\lambda=260$ & 0.0106 & 0.3986 & 0.9999 & 0.040 & 0.132 & $0.51-20.37$ \\
\hline Protocatechuic aldehyde & $\lambda=320$ & -0.0676 & 0.5102 & 0.9997 & 0.384 & 1.281 & $0.39-15.43$ \\
\hline Gentisic acid & $\lambda=320$ & -0.0777 & 0.2378 & 0.9990 & 1.433 & 4.777 & $2.51-40.10$ \\
\hline$(+)$-Catechin & $\lambda_{\mathrm{ex}}=280 ; \lambda_{\mathrm{emi}}=310$ & 0.0583 & 7.3050 & 0.9999 & 0.027 & 0.090 & $0.11-4.25$ \\
\hline Vanillinic acid & $\lambda=260$ & -0.0276 & 0.6179 & 0.9998 & 0.095 & 0.121 & $0.56-22.43$ \\
\hline Caffeic acid & $\lambda=320$ & -0.0231 & 0.8846 & 0.9998 & 0.050 & 0.167 & $0.25-10.08$ \\
\hline Vanillin & $\lambda=320$ & -0.0169 & 0.4869 & 0.9999 & 0.150 & 0.498 & $0.39-15.65$ \\
\hline Epicatechin & $\lambda_{\mathrm{ex}}=280 ; \lambda_{\mathrm{emi}}=310$ & 0.0241 & 6.3546 & 0.9998 & 0.020 & 0.065 & $0.08-3.33$ \\
\hline Syringic aldehyde & $\lambda=260$ & -0.0144 & 0.0655 & 0.9997 & 0.344 & 1.145 & $1.26-50.40$ \\
\hline p-Coumaric acid & $\lambda=260$ & -0.014 & 0.3089 & 0.9998 & 0.081 & 0.270 & $0.13-5.22$ \\
\hline Ferulic acid & $\lambda=320$ & -0.1243 & 0.8083 & 0.9999 & 0.149 & 0.496 & $0.56-22.52$ \\
\hline Sinapic acid & $\lambda=320$ & -0.0655 & 0.7459 & 0.9999 & 0.192 & 0.641 & $0.76-30.29$ \\
\hline Resveratrol & $\lambda_{\mathrm{ex}}=310 ; \lambda_{\mathrm{emi}}=403$ & -0.0713 & 10.4320 & 0.9999 & 0.013 & 0.042 & $0.02-0.97$ \\
\hline
\end{tabular}

Absorbance $=a+b \times$ concentration $\left(\mathrm{mg} \mathrm{L}^{-1}\right)$

\section{Statistical Software}

The limits of detection and quantification have been calculated using ALAMIN software [28]. Regression equations, correlation coefficients and relative standard deviations were calculated using Excel 2007 software (Microsoft, Redmond, WA, USA).

\section{Results and Discussion}

\section{Isocratic Methods}

Initially the development of the method was begun with a flow of $2.5 \mathrm{~mL} \mathrm{~min}{ }^{-1}$. The solvents customarily utilised in the separation of these compounds in methods developed with classical columns were employed as mobile phase [29]. First, various different methods for the separation of polyphenol standards present in the mixture were studied in isocratic elution. Six methods in isocratic elution were tested: method 1 (100\% solvent A); method 2 (97\% solvent A); method 3 (94\% solvent A); method 4 ( $91 \%$ solvent A); method 5 (88\% solvent A) and method 6 ( $85 \%$ solvent $A)$. It was decided to limit the analysis time to $15 \mathrm{~min}$; hence data of peaks eluting afterwards were not collected. The temperature in the column was held constant at $25{ }^{\circ} \mathrm{C}$.

Table 1 shows that, employing methods 1 and 2, there was not a good separation of the peaks corresponding to compounds siringaldehyde and $p$-coumaric acid. However, separation between the compounds analysed was obtained with methods 3 and 4 (94\% $\mathrm{A}$ and $91 \% \mathrm{~A})$. When the percentage of the more polar solvent was as low as $88 \%$ (method 5) peak overlapping of three other compounds; epicatechin, vanillinic acid and caffeic acid occurred. Nevertheless, epicatechin can be quantified individually employing the signal recorded by the fluorescence detector.

The isocratic method 3 is not considered adequate since the latter peak eluted presents a retention time of more than $15 \mathrm{~min}$. Employing the isocratic method 4 (91\% of solvent A), all the compounds were eluted in a time of less 
than 15 min. With this method the values of resolution were found to be higher than 1.9 for all the compounds, with the exception of the pairs: gentisic acidvanillinic acid and vanillinic acid-caffeic acid.

Thus, the isocratic methods 3 and 4 represent good starting points for the development of gradient methods that allow separation in shorter times.

\section{Gradient Method}

Taking isocratic methods as the base, the following gradient (time ( $\mathrm{min}$ ), solvent A (\%)) was assayed: $0,100 \% ; 1,94 \% ; 4$, $94 \% ; 5,87 \% ; 6,60 \% ; 9,50 \% ; 14,0 \%$. As can be observed in this gradient method, between 0 and $4 \mathrm{~min}$, the combination of isocratic methods 1 and 3 was utilised, with the intention of obtaining the separation of the compounds vanillinic acid and caffeic acid.

Figure 2 shows the resulting chromatogram. Therefore, an acceptable complete separation of the compounds studied was obtained, with a good resolution of the chromatographic peaks, and with a very substantial shortening of the analysis time, especially for resveratrol, when compared with the isocratic methods.

\section{Selection of the Temperature}

After developing the optimum gradient of separation of the polyphenols present in the standard mixture, the effect of the column temperature on the chromatographic resolution of the peaks was studied, with the same gradient as described above. The study was conducted using different column temperatures (15, $25,30,35$ and $40{ }^{\circ} \mathrm{C}$ ). The flow rate of

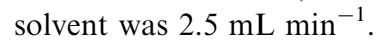

Table 2 presents the resolution of the chromatographic peaks corresponding to each of the polyphenols studied, at the temperature tested. From these data it can be concluded that is possible to employ temperatures between 15 and $25{ }^{\circ} \mathrm{C}$ for obtaining good resolutions of the compounds assayed. The best results were obtained at $25^{\circ} \mathrm{C}$. Temperatures

Table 5. Repeatability ( $n=9$ in the same day) and reproducibility ( $n=9$ in 3 different days) of the method developed expressed as Relative Standard Deviations (RSD)

\begin{tabular}{|c|c|c|c|c|}
\hline \multirow[t]{2}{*}{ Compound } & \multicolumn{2}{|l|}{ Repeatability } & \multicolumn{2}{|c|}{ Reproducibility } \\
\hline & Intra-day $(k)$ & Intra-day (Area) & Inter-day $(k)$ & Inter-day (Area) \\
\hline Gallic acid & 1.8 & 0.1 & 2.0 & 1.2 \\
\hline $\begin{array}{l}\text { Protocatechuic } \\
\text { aldehyde }\end{array}$ & 0.1 & 0.6 & 1.1 & 0.4 \\
\hline Gentisic acid & 0.7 & 2.3 & 0.7 & 2.1 \\
\hline$(+)$-Catechin & 1.4 & 0.4 & 1.1 & 0.4 \\
\hline Vanillinic acid & 0.9 & 0.9 & 0.9 & 1.6 \\
\hline Caffeic acid & 1.3 & 1.2 & 0.9 & 2.5 \\
\hline Vanillin & 1.1 & 0.6 & 0.9 & 0.5 \\
\hline Epicatechin & 1.8 & 0.3 & 1.2 & 0.8 \\
\hline Syringic aldehyde & 1.6 & 0.4 & 1.0 & 0.5 \\
\hline p-Coumaric acid & 1.4 & 0.9 & 0.9 & 1.7 \\
\hline Ferulic acid & 1.0 & 0.5 & 0.9 & 1.5 \\
\hline Sinapic acid & 0.6 & 1.0 & 0.4 & 1.6 \\
\hline Resveratrol & 0.1 & 0.8 & 0.2 & 0.9 \\
\hline
\end{tabular}

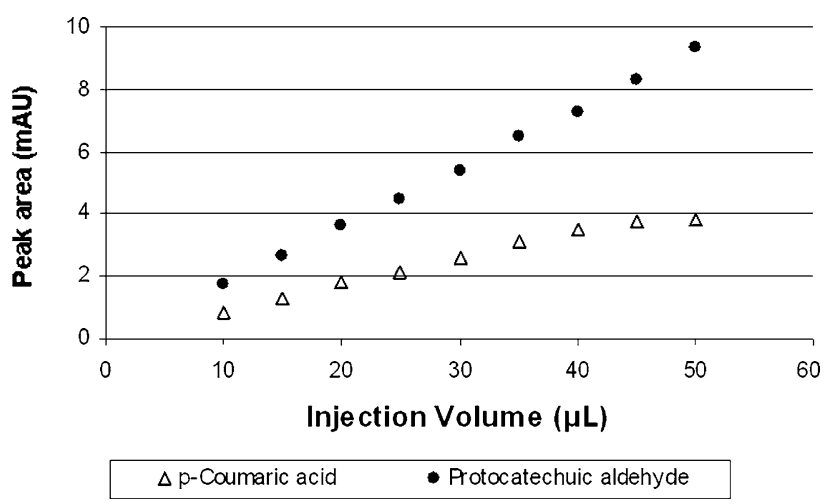

Fig. 3. Effect of the injection volume on the peak areas of $p$-coumaric acid and protocatechuic aldehyde

higher than $25^{\circ} \mathrm{C}$ produce a loss of resolution, principally between peaks corresponding to the groups: syringic aldehyde and $p$-coumaric acid; and gentisic acid, catechin, vanillinic acid and caffeic acid (although, as stated, catechin can be quantified individually employing the signal recorded by the fluorescence detector).

\section{Selection of the Flow Rate}

The influence of the flow rate of the mobile phase on the chromatographic resolution was studied and flow rates of $2,2.5,3,3.5,4,4.5$ and $5 \mathrm{~mL} \mathrm{~min}^{-1}$ were employed.

Table 3 shows the resolutions of the chromatographic peaks corresponding to the polyphenols studied at different flow rates. It can be confirmed that good chromatographic resolutions were obtained with solvent flow rates of up to $2.5 \mathrm{~mL} \mathrm{~min}^{-1}$. At flow rates higher than $3 \mathrm{~mL} \mathrm{~min}^{-1}$ some peaks (syringaldehyde and $p$-coumaric acid) were not resolved. Between 2 and $2.5 \mathrm{~mL} \mathrm{~min}^{-1}$ the differences between the resolutions obtained were small; therefore the higher rate was selected as the working flow rate, since it gave a slightly shorter total analysis time (7.25 $\mathrm{min}$ vs $7.73 \mathrm{~min}$ ).

\section{Characteristics of the Method}

Calibration curves were produced with the method developed. The results obtained are presented in Table 4. 
Table 6. Effect of the different percentages of methanol on the resulting peak areas

\begin{tabular}{|c|c|c|c|c|c|c|}
\hline \multirow[t]{3}{*}{ Compound } & \multicolumn{6}{|c|}{ Sample solvent } \\
\hline & \multicolumn{2}{|l|}{ Water } & \multicolumn{2}{|c|}{$\begin{array}{l}\text { Water:Methanol } \\
(1: 1)\end{array}$} & \multicolumn{2}{|l|}{ Methanol } \\
\hline & Peak area & $R T$ & Peak area & $R T$ & Peak area & $R T$ \\
\hline Gallic acid & $3.46^{\mathrm{a}}$ & 0.89 & $3.61^{\mathrm{a}}$ & 0.87 & $3.63^{\mathrm{a}}$ & 0.87 \\
\hline Protocatechuic aldehyde & $4.39^{\mathrm{a}}$ & 1.66 & $4.46^{\mathrm{a}}$ & 1.63 & $4.24^{\mathrm{a}}$ & 1.63 \\
\hline Gentisic acid & $0.91^{\mathrm{a}}$ & 1.85 & $0.99^{\mathrm{a}}$ & 1.83 & $0.62^{\mathrm{b}}$ & 1.83 \\
\hline$(+)$-Catechin & $12.29^{\mathrm{a}}$ & 1.96 & $12.24^{\mathrm{a}}$ & 1.94 & $9.73^{\mathrm{b}}$ & 1.96 \\
\hline Vanillinic acid & $2.42^{\mathrm{a}}$ & 2.44 & $2.41^{\mathrm{a}}$ & 2.42 & $2.63^{\mathrm{b}}$ & 2.45 \\
\hline Caffeic acid & $2.32^{\mathrm{a}}$ & 2.61 & $2.37^{\mathrm{a}}$ & 2.58 & $1.31^{\mathrm{b}}$ & 2.60 \\
\hline Vanillin & $4.10^{\mathrm{a}}$ & 3.13 & $4.10^{\mathrm{a}}$ & 3.10 & $3.51^{\mathrm{b}}$ & 3.13 \\
\hline Epicatechin & $8.27^{\mathrm{a}}$ & 3.46 & $8.34^{\mathrm{a}}$ & 3.45 & $7.03^{\mathrm{b}}$ & 3.51 \\
\hline Syringic aldehyde & $6.52^{\mathrm{ab}}$ & 4.00 & $6.69^{\mathrm{a}}$ & 3.96 & $6.30^{\mathrm{b}}$ & 4.03 \\
\hline$p$-Coumaric acid & $2.13^{\mathrm{a}}$ & 4.26 & $2.16^{\mathrm{a}}$ & 4.22 & $1.37^{\mathrm{b}}$ & 4.28 \\
\hline Ferulic acid & $4.46^{\mathrm{a}}$ & 5.73 & $4.48^{\mathrm{a}}$ & 5.68 & $3.68^{\mathrm{b}}$ & 5.76 \\
\hline Sinapic acid & $2.79^{\mathrm{a}}$ & 6.40 & $2.87^{\mathrm{a}}$ & 6.39 & $2.28^{\mathrm{b}}$ & 6.42 \\
\hline Resveratrol & $4.03^{\mathrm{a}}$ & 7.24 & $4.00^{\mathrm{a}}$ & 7.24 & $3.75^{\mathrm{b}}$ & 7.25 \\
\hline
\end{tabular}

Means with the same superscripts (a-b) are not statistically different $(P<0.05)$. Means without superscripts $(\mathrm{a}-\mathrm{b})$ are not statistically different $(P<0.05)$
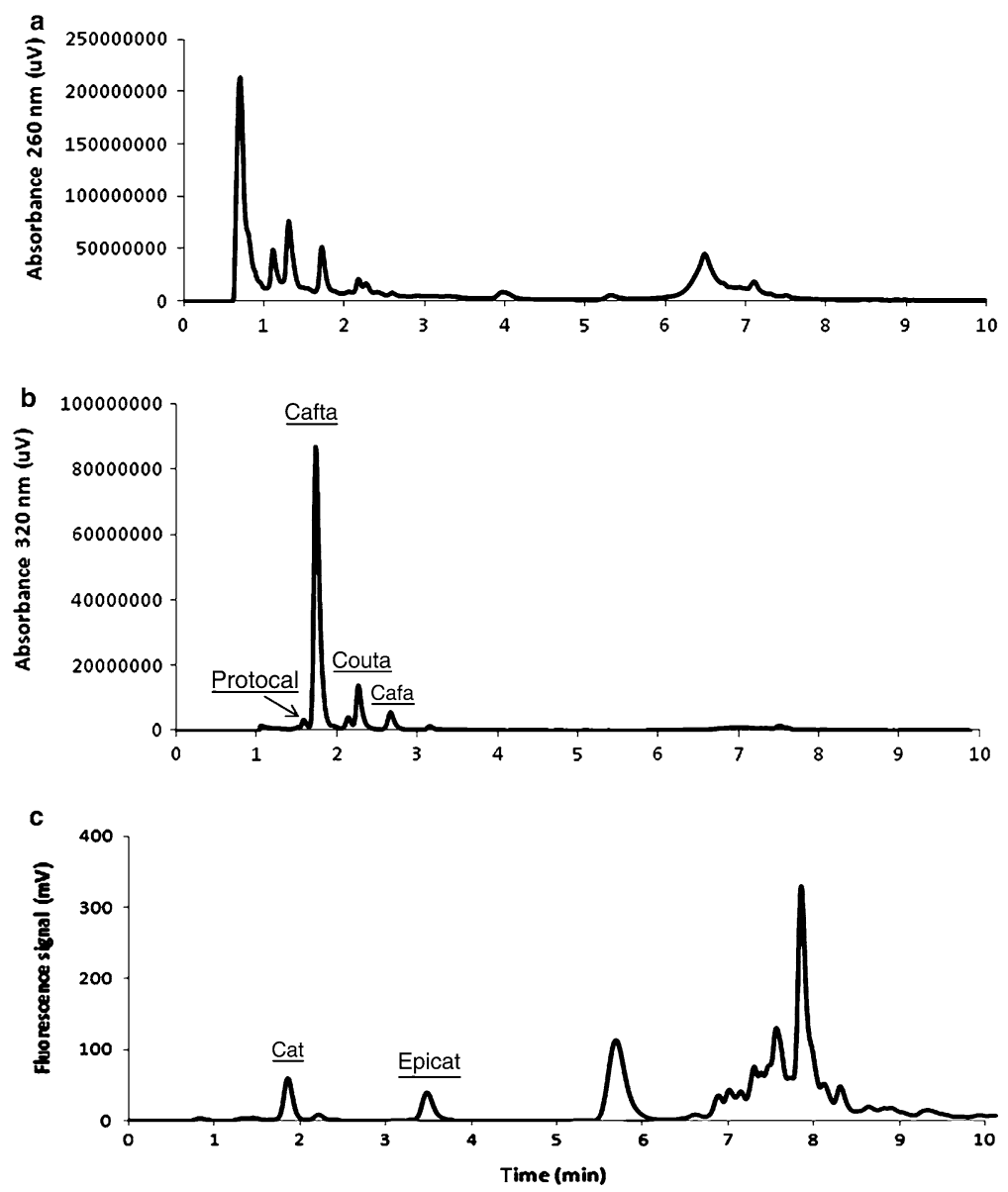

Fig. 4. Chromatograms obtained from real samples employing the final method. Detection conditions: diode array detector: $\lambda=260 \mathrm{~nm}(\mathbf{a}), \lambda=320 \mathrm{~nm}(\mathbf{b})$. Fluorescence detector (excitation/emission) (c): 280/310 (from start until $7.0 \mathrm{~min}$ ) and 310/403 (from $7.0 \mathrm{~min}$ until the end). Protcal: protocatechuic aldehyde, Cafta: caftaric acid, Couta: coutaric acid, Cafa: caffeic acid, Cat: (+)-catechin, Epicat: epicatechin
Using the final optimised conditions, a total of 15 chromatographic analyses of the same sample have been performed, distributed as follows: 9 analyses performed on the same day (repeatability) and 3 more analyses on each of the two consecutive days (reproducibility). The repeatability and reproducibility of the method developed has been studied both for the peak area of each phenolic compound and for the retention factor of the compounds. The results obtained, expressed as relative standard deviation for both the repeatability and the reproducibility in respect of the retention factor and the peak area, are given in Table 5.

It can be seen that for both parameters, the error was below $2.4 \%$ when measuring the repeatability of the method. In respect of the reproducibility, maximum variations of $2.5 \%$ in area and $2.0 \%$ in the retention factor were obtained.

\section{Robustness of the Method \\ Volume of Sample for Analysis}

To evaluate the effect of the injection volume on the retention factors and peak areas, a series of injections of different volumes $(10-50 \mu \mathrm{L})$ of the mixture of standards was performed. The errors obtained were low (average RSD = $1.27 \%$ ) ranging from $\mathrm{RSD}=0.19 \%$ for resveratrol to $\mathrm{RSD}=1.93 \%$ for epicatechin.

The influence of the injection volume on the peak area measured for two compounds ( $p$-coumaric acid and protocatechuic aldehyde) are shown in Fig. 3. It can be confirmed that for $p$-coumaric acid a linear relationship is found between the area and the injection volume for all the volumes assayed (10$50 \mu \mathrm{L}$ ), while for protocatechuic aldehyde, this linearity is only evident between 10 and $45 \mu \mathrm{L}$. This behaviour of protocatechuic aldehyde was also found for the compounds gentisic acid and caffeic acid. Therefore, injection volumes higher than $45 \mu \mathrm{L}$ are not allowed for the proposed method. 


\section{Sample Solvent}

The extraction methods used for real samples provide extracts with different proportions of organic solvent in water $[30,31]$. The presence of the organic solvent can introduce distortions in the chromatographic peaks; therefore it is necessary to evaluate the effect of the sample solvent on the peaks obtained. For this, a series of mixtures of standards prepared with different percentages of methanol $(0,50$ and $100 \%)$ in water was employed.

Table 6 presents the effect on the characteristics of the method, produced by the solvent of the mixture prepared. It must be emphasised that a significant effect was not found on the retention factors of the compounds analysed. In case of the peak area, it can be observed that there were no significant differences between the peak areas by employing percentages of methanol ranging from 0 to $50 \%$ in the sample. But, for a percentage of $100 \%$ of methanol, it was observed that there were significant differences for peak areas, as in compared to peak areas obtained with percentages of methanol from 0 to $50 \%$. Therefore, when the methanol in the samples exceeded $50 \%$, it was necessary first to eliminate part of methanol or to dilute it with water, to be able to utilise the developed method, without modifying the method of integration of the chromatographic peaks.

\section{Application to Real Samples}

The method developed has been applied in the determination of the polyphenols present in the musts originating from two varieties of grapes: Riesling (white) and Monastrell (red) collected at the beginning of the ripening. Sample preparation was by filtration through 0.45 micron filters. Sample injection volume was $25 \mu \mathrm{m}$. Figure 4 shows the resulting chromatograms for the Riesling variety.

In addition to some of the compounds employed in the development of the method, it was possible to quantify other compounds for which standards

Table 7. Amount of polyphenols $\left(\mathrm{mg} \mathrm{L}^{-1} \pm \mathrm{SD}\right.$ ) found in grape musts

\begin{tabular}{|c|c|c|c|}
\hline \multirow[t]{2}{*}{ Compound } & \multirow[t]{2}{*}{ Wavelength (nm) } & \multicolumn{2}{|l|}{ Grape variety } \\
\hline & & Riesling & Monastrell \\
\hline Protocatechuic aldehyde & $\lambda=320$ & $18.41 \pm 0.07$ & $7.29 \pm 0.03$ \\
\hline Caftaric acid ${ }^{\mathrm{a}}$ & $\lambda=320$ & $80.76 \pm 2.02$ & $27.12 \pm 0.68$ \\
\hline Caffeic acid & $\lambda=320$ & $1.44 \pm 0.04$ & $0.55 \pm 0.01$ \\
\hline Coutaric acid ${ }^{\mathrm{a}}$ & $\lambda=320$ & $3.93 \pm 0.07$ & $0.92 \pm 0.02$ \\
\hline$(+)$-Catechin & $\lambda_{\mathrm{ex}}=280 ; \lambda_{\mathrm{emi}}=310$ & $49.53 \pm 0.20$ & $73.94 \pm 0.30$ \\
\hline Epicatechin & $\lambda_{\mathrm{ex}}=280 ; \lambda_{\mathrm{mi}}=310$ & $40.18 \pm 0.32$ & $128.52 \pm 1.03$ \\
\hline
\end{tabular}

${ }^{\text {a }}$ Expressed as caffeic acid equivalents

are not commercially available, such as caftaric acid (caffeoyltartaric ester) and coutaric acid (coumaroyltartaric ester) which are also significant components of many varieties of grapes. The retention factors and quantities determined of the compounds identified in the real samples are presented in Table 7.

\section{Conclusions}

In this study a fast method using monolithic columns has been developed, which performs the separation of all phenolic compounds in less than 7.3 min. Using a mixture of water and methanol with acetic acid, the method provides reliable, high-resolution and reproducible results (RSD $<2.0 \%$ for both the retention factor and peak areas).

The optimised method can be applied to real samples (musts from both white and red grapes) containing different families of phenolics.

\section{Acknowledgments}

Authors are most grateful to the Agencia Española de Cooperación Internacional y Desarrollo (AECID) for supporting the research under the project A/010835/ 07.

\section{References}

1. Harborne JB (1989) In: Methods in plant biochemistry. Academic Press, London

2. Macheix JJ, Fleuriet A, Billot J (1990) In: Fruit phenolics. CRC Press, Boca Raton

3. Girard B, Yuksel D, Cliff MA, Delaquis P, Reynolds AG (2001) Food Res Int
34:483-499. doi:10.1016/S0963-9969(00) 00177-0

4. Young JF, Dragsted LO, Daneshvar B, Lauridsen ST, Hansen M, Sandstrom B (2000) Br J Nutr 84:505-513. doi: $10.1017 /$ S0007114500001811

5. Ferroni F, Maccaglia A, Pietraforte D, Turco L, Minetti M (2004) J Agric Food Chem 52:2866-2874. doi:10.1021 jf034270n

6. Burns J, Gardner PT, Oneil J, Crawford S, Morecroft I, McPhail DB, Lister C, Matthews D, Maclean MR, Lean MEJ, Duthie GG, Crozier A (2000) J Agric Food Chem 48:220-230. doi:10.1021/ jf9909757

7. Barroso CG, Rodríguez MC, Guillén DA, Pérez-Bustamante JA (1996) J Chromatogr A 724:125-129. doi:10. 1016/0021-9673(95)00985-X

8. Vitrac X, Bornet A, Vanderlinde R, Valls J, Richard T, Delaunay JC, Merillon JM, Teissedre PL (2005) J Agric Food Chem 53:5664-5669. doi:10.1021/jf050122g

9. Papagiannopoulos M, Wollseifen HR, Mellenthin A, Haber B, Galensa R (2004) J Agric Food Chem 52:3784-3791. doi: 10.1021/jf030660y

10. Hvattum E, Ekeberg D (2003) J Mass Spectrom 38:43-49. doi:10.1002/jms.398

11. Careri M, Corradini C, Elviri L, Nicoletti I, Zagnoni I (2003) J Agric Food Chem 51:5226-5231. doi:10.1021/jf034149g

12. Chilla C, Guillén DA, Barroso CG, Pérez-Bustamante JA (1996) J Chromatogr A 750:209-214. doi:10.1016/0021-9673 (96)00557-2

13. Castellari M, Sartini E, Fabiani A, Arfelli G, Amati A (2002) J Chromatogr A 973:221-227. doi:10.1016/S0021-9673 (02)01195-0

14. Maruska A, Kornyšova O (2006) J Chromatogr A 1112:319-330. doi: 10.1016/j.chroma.2006.01.099

15. Kele M, Guiochon G (2002) J Chromatogr A 960:19-49. doi:10.1016/S00219673(01)01227-4

16. Apers S, Naessens T, Van Den Steen K, Cuyckens F, Claeys M, Pieters L, Vlietinck A (2004) J Chromatogr A 1038:107112. doi:10.1016/j.chroma.2004.03.033

17. Chinnici F, Gaiani A, Natali N, Riponi C, Galassi S (2004) J Agric Food Chem 52:3-7. doi:10.1021/jf030459n

18. Abert Vian M, Tomao V, Gallet S, Coulomb PO, Lacombe JM (2005) J 
Chromatogr A 1085:224-229. doi: 10.1016/j.chroma.2005.05.083

19. Barbero GF, Palma M, Barroso CG (2006) J Agric Food Chem 54:3231-3236. doi:10.1021/jf060021y

20. Rostagno MA, Palma M, Barroso CG (2005) J Chromatogr A 1076:110-117. doi:10.1016/j.chroma.2005.04.045

21. Suárez B, Picinelli A, Mangas JJ (1996) J Chromatogr A 727:203-209. doi:10.1016/ 0021-9673(95)01175-7

22. Castellari M, Matricardi L, Arfelli G, Galassi S, Amati A (2000) Food Chem 69:61-67. doi:10.1016/S0308-8146(99) 00240-X
23. Spáčil Z, Nováková L, Solich P (2008) Talanta 76:189-199. doi:10.1016/ j.talanta.2008.02.021

24. Schwarz M, Rodríguez MC, Guillén DA, Barroso CG (2009) J Sep Sci 32:17821790. doi: $10.1002 /$ jssc. 200800706

25. Cicchetti E, Chaintreau A (2009) J Sep Sci 32:3043-3052. doi:10.1002/jssc.200900132

26. Piñeiro Z, Palma M, Barroso CG (2004) J Chromatogr A 1026:19-23. doi:10.1016/ j.chroma.2003.10.096

27. Piñeiro Z, Palma M, Barroso CG (2006) J Chromatogr A 1110:61-65. doi:10.1016/ j.chroma.2006.01.067
28. García Campaña AM, Cuadros Rodríguez L, Alés Barrero F, Ceba MR, Sierra Fernández JL (1997) Trends Anal Chem 16:381-385. doi:10.1016/S0165-9936 (97)00049-6

29. Guillén DA, Barroso CG, Pérez-Bustamante JA (1996) J Chromatogr A 724:117-124. doi:10.1016/0021-9673(95) 00931-0

30. Palma M, Piñeiro Z, Barroso CG (2002) J Chromatogr A 968:1-6. doi:10.1016/ S0021-9673(02)00823-3

31. Palma M, Taylor LT (1999) J Chromatogr A 849:117-124. doi:10.1016/S00219673(99)00569-5 